\title{
Tool wear of sintered cubic boron nitride compact in cutting hardened steel with high-pressure coolant supplied
}

\author{
T. Wada ${ }^{1}$, K. Okayama ${ }^{1}$ \& Y. Morigo ${ }^{2}$ \\ ${ }^{1}$ Department. of Mechanical Engineering, \\ Nara National College of Technology, Japan \\ ${ }^{2}$ TOKUPI Corporation, Japan
}

\begin{abstract}
Hardened steel is used for dies and molds, and is quenched and tempered to improve its mechanical properties and wear resistance. For dimensional accuracy, hardened steel is machined by a metal removal process. High-speed cutting is an effective method of improving productivity. As, the cutting temperature rises very high in high-speed cutting, the tool materials require both good wear-resistance and heat-resistance, and the cutting parts must be cooled for efficacy and efficiency. In this study, hardened steel was turned with a high-pressure coolant supplied, the chip configurations, the tool wear and the surface roughness were experimentally investigated. The hardened steel used was an ASTM D2 coldworked die steel (60HRC). The results are as follows: (1) In turning with a highpressure coolant supplied, the effectiveness of chip breaking performance was improved. In this case, the chip length was shorter with the increase of the coolant pressure, and the chip length was longer with the increase of the cutting speed. (2) In the case of a cutting speed of $10.00 \mathrm{~m} / \mathrm{s}$, large wear on the flank face was observed in the dry cutting. It was possible to suppress the tool wear on the flank face with a high-pressure coolant supplied. (3) In the high-pressure coolant cutting method of hardened steel with a cBN tool at a cutting speed of $10.00 \mathrm{~m} / \mathrm{s}$, a cBN grain size of $5.0 \mu \mathrm{m}, 45 \mathrm{cBN}$ grain $/ 55$ binding phase and main element of the binder phase of TiCN-Al was an effective tool material. The surface roughness by cutting with this $\mathrm{cBN}$ tool was almost constant up to a cutting distance of $1080 \mathrm{~m}$. Keywords: sintered cubic boron nitride compact ( $c B N)$, hardened steel, highpressure coolant supplied, machinability.
\end{abstract}




\section{Introduction}

Hardened steel is used for dies and molds, and is quenched and tempered to improve its mechanical properties and wear resistance. For dimensional accuracy, hardened steel is machined by the metal removal process. High-speed cutting is an effective method of improving productivity. As, the cutting temperature rises very high in high-speed cutting, the tool materials require both good wear-resistance and heat-resistance, and the cutting parts must be cooled for efficacy and efficiency.

Polycrystalline cubic boron nitride compact (cBN) seems to be an effective tool material because it has better features as a tool material such as hardness, heatresistance, etc. There are many studies on the tool wear of $\mathrm{cBN}$ tools [1-4]. However, the cutting performance of $\mathrm{cBN}$ tools depends on the content of both the $\mathrm{cBN}$ grain and the binding phase [5], the binding phase [6]. Therefore, an effective binding phase, etc. for $\mathrm{cBN}$ tools should be selected for cutting hardened steel.

High-pressure coolant cutting is effective for reducing the cutting temperature. For this reason, many studies on high-pressure coolant cutting have recently been carried out.

Itakura et al. [7] reported that high speed cutting of Inconel 718 was attempted at increased cutting fluid flow rate by injecting fluid at a high pressure to the cutting edge. As a result, as the injection speed of the cutting fluid went up, the cutting temperature was reduced and flank wear was reduced. Thus, high-pressure coolant cutting is considered effective for reducing tool wear [8-10]. Further, the improvement of chip control, particularly chip breaking performance, is also expected by the high-pressure coolant supplied [11].

However, the influences of both the cutting speed and the coolant pressure on merchantability in high-speed cutting hardened steel with high-pressure coolant supplied have not been reported.

In this study, in order to identify an effective cBN tool for the high-pressure coolant cutting of hardened steel, the influences of the cBN content, the cBN particle size and the binding phase on tool wear at various cutting speeds and coolant pressures were experimentally investigated. The hardened steel used was an ASTM D2 cold-worked die steel (60HRC). The hardened steel was turned with high-pressure coolant supplied, the chip configurations, the tool wear and the surface roughness were experimentally investigated.

\section{Experimental procedures}

The work material used is ASTM D2 cold-worked die steel (60HRC). The chemical composition of the hardened steel is shown in Table 1.

The cutting materials used are shown in Table 2 . cBN tools combine different contents ratios and different $\mathrm{cBN}$ particle sizes with a Ti-Al-based binding material. The configuration of the tool insert was ISO TNGA160408. The insert was attached to the tool holder PTJNL 2525M16JETL (Seco Tools AB). In this case, the tool geometry was $(-6,-6,6,6,23,-7,0.8 \mathrm{~mm})$. The insert had a chamfered and honed cutting edge, namely the width of the chamfered edge was 
$0.13 \mathrm{~mm}$, the angle of the chamfered edge was $25^{\circ}$ and the radius of the honed edge was $0.15 \mathrm{~mm}$.

Table 1: Chemical composition of work piece (ASTM D2).

\begin{tabular}{|c|c|c|c|c|c|c|}
\hline \multicolumn{1}{|c}{} & Cr & Mo & Mn & Si & V & Ni \\
\hline 1.45 & 11.6 & 0.81 & 0.36 & 0.23 & 0.22 & 0.12 \\
\hline
\end{tabular}

Table 2: $\quad$ Properties of sintered cubic boron nitride compact.

\begin{tabular}{|c|c|c|c|c|c|}
\hline $\begin{array}{c}\text { Tool } \\
\text { material }\end{array}$ & $\begin{array}{c}\text { Binding } \\
\text { phase }\end{array}$ & $\begin{array}{c}\text { Contents } \\
\text { rate } * *\end{array}$ & $\begin{array}{c}\text { Grain size } \\
\text { of cBN } \\
{[\mu \mathrm{m}]}\end{array}$ & $\begin{array}{c}\text { Hardness } \\
{[\mathrm{HV}]}\end{array}$ & $\begin{array}{c}\text { T. R. S. } \\
{[\mathrm{GPa}]}\end{array}$ \\
\hline cBN A & TiCN-Al & $45 / 55$ & 5.0 & $2700-2900$ & $0.80-0.90$ \\
\hline cBN B & TiN-Al & $65 / 35$ & 3.0 & $3200-3400$ & $1.00-1.10$ \\
\hline cBN C & TiN-Al & $75 / 25$ & 5.0 & $3500-3700$ & $1.15-1.30$ \\
\hline
\end{tabular}

*: Main element, **: (cBN grain/ binding phase),

T. R. S.: Transverse-rupture strength

Table 3: Coolant supply condition in high-pressure cutting.

\begin{tabular}{|l|l|}
\hline Coolant & $\begin{array}{l}\text { Water-soluble coolant } \\
\text { (YUSHIROKEN FGS650) }\end{array}$ \\
\hline Coolant concentration dilution & $10 \% \pm 3 \%$ \\
\hline Coolant supply pressure & $7,20 \mathrm{MPa}$ \\
\hline
\end{tabular}

Table 4: Cutting conditions.

\begin{tabular}{|l|l|}
\hline Cutting speed & $\mathrm{V}=5.00,7.50,10.00 \mathrm{~m} / \mathrm{s}$ \\
\hline Feed rate & $\mathrm{f}=0.05 \mathrm{~mm} / \mathrm{rev}$ \\
\hline Depth of cut & $\mathrm{ap}=0.1 \mathrm{~mm}$ \\
\hline Cutting method & Dry cutting, Wet (High-pressure coolant cutting) \\
\hline
\end{tabular}

Turning tests were carried out on a universal lathe (Type SL-25, DMG MORI COMPANY LIMITED) by adding a variable-speed drive. The driving power of this lathe is $11 / 15 \mathrm{~kW}$ and the maximum rotational speed is $4200 \mathrm{~min}^{-1}$.

The high-pressure coolant is directed via two nozzles on the tool holder, namely, the coolant is injected at high pressure to both the rake face and flank face by nozzle "A" and "B" as shown Fig. 1, respectively. A high-pressure coolant unit was used HIPRECO185-20 (TOKUPI Corporation). The maximum pressure is $20 \mathrm{MPa}$ and the maximum pump water suction is $45 \mathrm{~L} / \mathrm{min}$. Table 3 shows the 
coolant supply condition of high-pressure coolant cutting. In the case of the coolant pressure of $7 \mathrm{MPa}$ or $20 \mathrm{MPa}$, the pump water suction is $16 \mathrm{~L} / \mathrm{min}$ or $28 \mathrm{~L} / \mathrm{min}$, respectively.

The hardened steel was turned with high-pressure coolant supplied under the cutting conditions shown in Table 4. The chip configurations, the tool wear and the surface roughness were experimentally investigated.

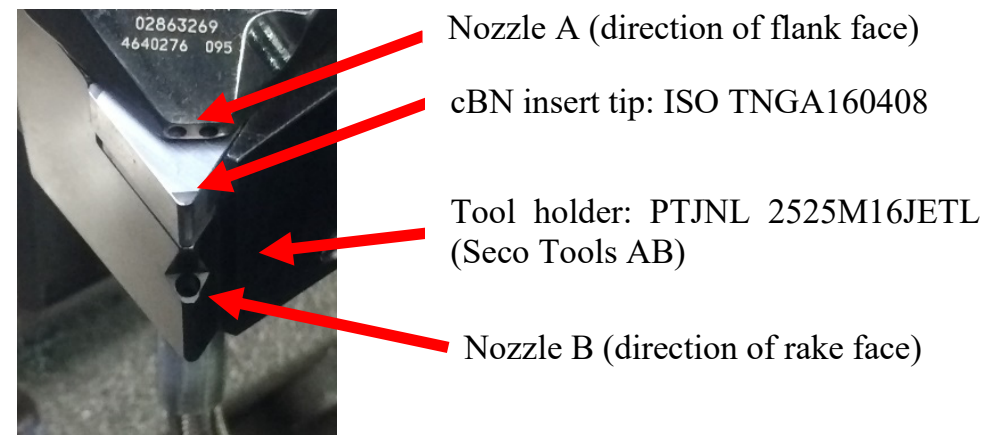

Figure 1: Method of injection of coolant.

\section{Results and discussion}

Hardened steel was cut with high-pressure coolant supplied at a feed rate of 0.05 $\mathrm{mm} / \mathrm{rev}$ and depth of cut of $0.1 \mathrm{~mm}$. Figure 2 shows the chips obtained during turning the hardened steel with a cBN A tool. The chip configuration changes depending on the progress of tool wear. Therefore, in the case of small tool wear, namely near the start of cutting, the chips were collected. Figure 2(i) shows the influence of coolant pressure on chip configuration at a constant cutting speed of $10.00 \mathrm{~m} / \mathrm{s}$. In the case of dry cutting shown in Fig. 2i(a), the chip configuration is continuous. The reason for this is as follows: Thin chips are produced under the cutting conditions of both a low feed rate and a small depth of cut. The thin chips are not broken due to the chip breaker not forming on the rake face of the insert tip. Therefore, continuous chips are produced in dry cutting.

In the case of high-pressure coolant cutting, the chips are broken at a coolant pressure of 7 and $30 \mathrm{MPa}$ as shown in Fig. 2i(b) and i(c), respectively.

In turning by insert tip with a grooved chip breaker, a running chip is subjected to bending action by the chip breaker and is forced to curl. In this case, the bending moment of the chip increases with the decrease of the radius curvature of the chip. The curled chip collides with the workpiece or the flank face of the insert tip. As the bending strain of the chip grows bigger, the chip is broken. In the case of highpressure coolant cutting, the pressure of the fluid acts as a chip breaker. Comparing the coolant pressure of $7 \mathrm{MPa}$ shown in Fig. 2i(b) and that of $20 \mathrm{MPa}$ shown in Fig. 2i(c), the length of the breaking chip at a coolant pressure of $20 \mathrm{MPa}$ is shorter 
than that of $7 \mathrm{MPa}$ because the bending strain increases with the increase of coolant pressure.

Figure 2(ii) shows the influence of cutting speed on chip configuration at a constant coolant pressure of $20 \mathrm{MPa}$. As compared with the cutting speed of 5.00, 7.50 and $10.00 \mathrm{~m} / \mathrm{s}$ shown in Fig. ii(a), ii(b) and ii(c) respectively, the length of the breaking chip increases with the increase of cutting speed because the thickness of the chip becomes thinner with the increase of cutting speed, and the bending strain decreases.

As mentioned above, chip breaking performance can be improved by using a high-pressure coolant method in cutting hardened steel.

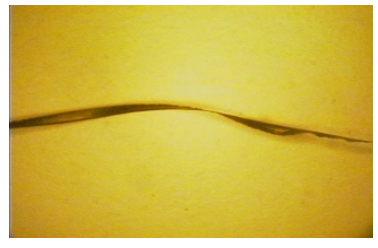

(a) $\operatorname{Dry}(\mathrm{P}=0 \mathrm{MPa})$

(b) $\mathrm{P}=7 \mathrm{MPa}$

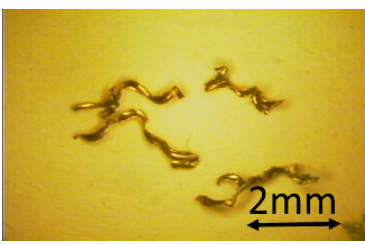

(c) $\mathrm{P}=20 \mathrm{MPa}$

(i) Influence of coolant pressure "P" on chip configuration at a constant cutting speed of $10.00 \mathrm{~m} / \mathrm{s}$

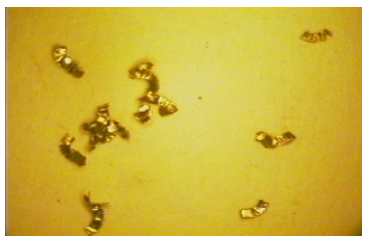

(a) $\mathrm{V}=5.00 \mathrm{~m} / \mathrm{s}$ pressure of $20 \mathrm{MPa}$

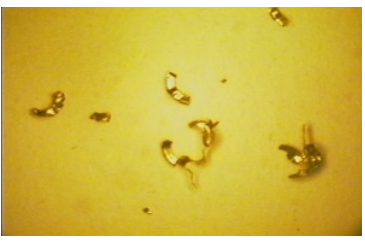

(b) $\mathrm{V}=7.50 \mathrm{~m} / \mathrm{s}$

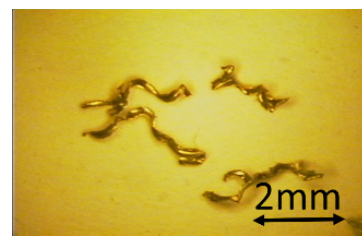

(c) $\mathrm{V}=10.00 \mathrm{~m} / \mathrm{s}$

Figure 2: Chip generated when turning hardened steel by $\mathrm{cBN}$ A tool at a feed rate of $0.05 \mathrm{~mm} / \mathrm{rev}$ and depth of cut of $0.1 \mathrm{~mm}$.

The tool wear was observed when turning hardened steel with various CBN tools. Figure 3 shows the tool wear in cutting hardened steel at a cutting speed of $10.00 \mathrm{~m} / \mathrm{s}$ and a cutting distance of $376 \mathrm{~m}$. Figure 3(i) and (ii) show the case of dry cutting and high-pressure cutting, respectively. In the case of dry cutting shown in Fig. (i), the wear is seen on the flank face of the corner. In particular, the damage of the $\mathrm{CBN} \mathrm{C}$ tool is intense. In the case of high-pressure coolant cutting shown in Fig. (ii), the wear is seen on the flank face of the corner, too. However, as compared with Fig. (i) and (ii), it is considered that the damage of the $\mathrm{cBN}$ tool is reduced with high-pressure coolant supplied. 
In high-pressure coolant cutting, characteristic wear, such as chipping or boundary wear, are not observed.

As mentioned above, the main tool failure of all tools in high-pressure coolant cutting is considered to be flank wear within the maximum value of the flank wear width of about $0.15 \mathrm{~mm}$. Therefore, the maximum value of flank wear width "VBmax" was measured with a laser scanning microscope.

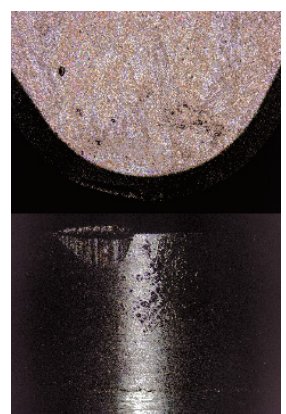

(a) cBN A

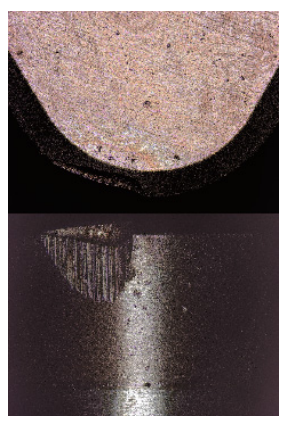

(b) $\mathrm{cBN} B$

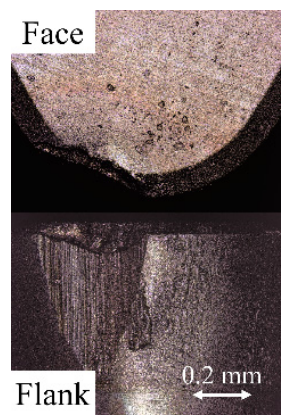

(c) $\mathrm{cBN} \mathrm{C}$

(i) Dry cutting at a cutting distance of $376 \mathrm{~m}$.

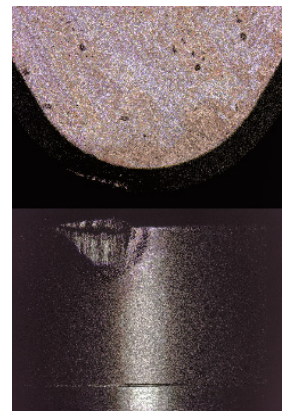

(a) $\mathrm{cBN}$ A, L $=1168 \mathrm{~m}$

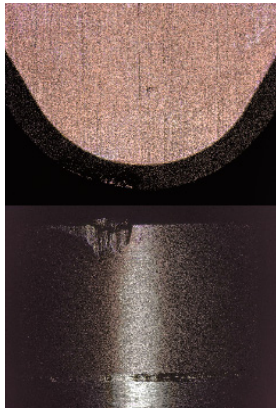

(b) $\mathrm{cBN}$ B, L=729 m

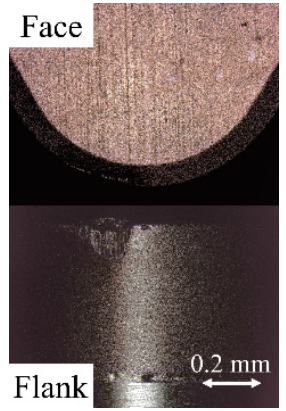

(c) $\mathrm{cBN} \mathrm{C}, \mathrm{L}=729 \mathrm{~m}$

(ii) High-pressure coolant cutting at a coolant pressure of $20 \mathrm{MPa}$

Figure 3: Tool wear in cutting hardened steel at a cutting speed of $10.00 \mathrm{~m} / \mathrm{s}$.

Figure 4 shows the relation between the cutting distance " $L$ " and the maximum flank wear width "VBmax" in high-pressure cutting of hardened steel with three kinds of $\mathrm{cBN}$ tools. When three kinds of $\mathrm{cBN}$ tools are compared, the wear progress of the $\mathrm{cBN} A$ is the slowest. The reason for this is as follows.

Kato et al. [12] cut austempered bainitic spheroidal graphite cast iron with $\mathrm{cBN}$ tools of different sintered elements, that is, the binder phase, the grain size of $\mathrm{cBN}$ and the content of both the $\mathrm{cBN}$ grain and the binding phase. And, they reported that the optimum combination of both the $\mathrm{cBN}$ grain and the binding phase is about $40 \mathrm{cBN}$ grain/60 binding phase in which the thickness of the 
binding phase is $3 \mu \mathrm{m}$. In the case of $\mathrm{cBN}$ A, which has a cBN grain size of $5.0 \mu \mathrm{m}$ and $45 \mathrm{cBN}$ grain $/ 55$ binding phase, the thickness of the binding phase is $4.1 \mu \mathrm{m}$. In the case of $\mathrm{cBN} \mathrm{B}$, which has a $\mathrm{cBN}$ grain size of $3.0 \mu \mathrm{m}$ and $65 \mathrm{cBN}$ grain//35 binding phase, the thickness of the binding phase is $4.1 \mu \mathrm{m}$. In the case of $\mathrm{cBN} \mathrm{C}$, which has a cBN grain size of $5.0 \mu \mathrm{m}$ and $75 \mathrm{cBN}$ grain//25 binding phase, the thickness of the binding phase is $1.1 \mu \mathrm{m}$.

Furthermore, the main element of the binding phase of $\mathrm{cBN}$ A is $\mathrm{TiCN}$, and the main element of the binding phase of both $\mathrm{cBN} B$ and $\mathrm{cBN} C$ is TiN. So, the wear progress of the $\mathrm{cBN}$ tool is considered to have an influence on the main element of the binding phase. Namely, the properties of the main element of the binding phase is considered. Jindal et al. [13] reported that the hardness of TiCN was higher than that of TiN in the range of temperature from $25^{\circ} \mathrm{C}$ to $1000^{\circ} \mathrm{C}$. And, in turning of Inconel 718, medium carbon SAE 1045 steel, and ductile iron at low and high cutting speeds, the tool life of the TiCN coated carbide tool was longer than that of TiN. Te-Hua Fang et al. [14] reported that the SPM and the nanoindentation technique were carried out for TiN and TiCN thin films deposited on silicon ( $\left.\begin{array}{lll}1 & 0 & 0\end{array}\right)$ substrate using the PECVD method to investigate their microstructures and nanomechanical properties. The results show that hardnesses for TiCN and TiN ranged from 11.84 to $14.09 \mathrm{GPa}$ and from 8.24 to $11.02 \mathrm{GPa}$, respectively. Takadoum et al. [15] reported the average hardness values and the following results were obtained: TiCN, $2600 \pm 65$; and TiN, $2100 \pm 55$.

As mentioned above, the wear-resistance of $\mathrm{TiCN}$, which is the main element of the binding phase of the $\mathrm{cBN} A$ is better than that of TiN, which is the main element of the binding phase of the $\mathrm{cBN}$ B or $\mathrm{cBN}$ C. So, it is considered to be one of the reasons for the excellent wear resistance of $\mathrm{cBN}$ A tool, which is the main element of the binding phase of TiCN.

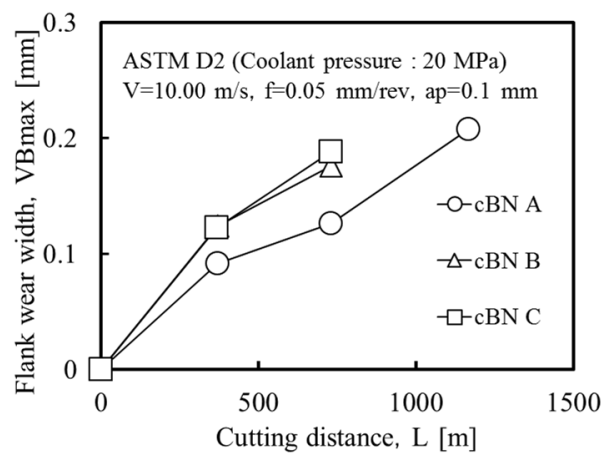

Figure 4: Relation between cutting distance and flank wear width in highpressure cutting hardened steel at a cutting speed of $10.00 \mathrm{~m} / \mathrm{s}$ and a coolant pressure of $20 \mathrm{MPa}$. 
Figure 5 shows the profile of the machined surface along the feed direction. In the profile curves shown in Fig. 5, the lower part of the profile curve is the workpiece. Figure (a) shows the case of a cutting distance "L" of $31 \mathrm{~m}$ and Fig. (ii) shows the case of a cutting distance "L" of $1080 \mathrm{~m}$. At the short cutting distance of $31 \mathrm{~m}$, the obvious feed marks have the pitch of a feed rate of $0.05 \mathrm{~mm} / \mathrm{rev}$. However, as the wear progresses, for example, at the long cutting distance of $1080 \mathrm{~m}$, although the feed marks are recognized, the profile valleys of the feed marks become random. However, in these experiments shown Fig. 5, no remarkable findings were observed in the built-up edge or the chattering vibration.

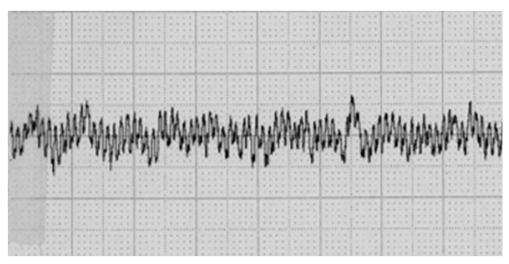

(a) $\mathrm{L}=31 \mathrm{~m}, \mathrm{Rz}=1.05 \mu \mathrm{m}$

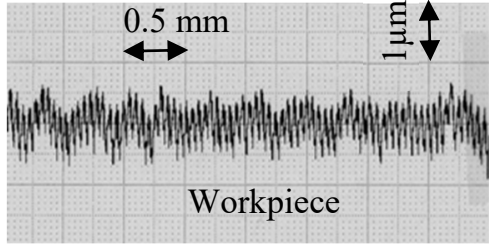

Feed direction

(b) $\mathrm{L}=1080 \mathrm{~m}, \mathrm{Rz}=1.31 \mu \mathrm{m}$

Figure 5: Profile curve of the machined surface in high-pressure coolant cutting with $\mathrm{cBN}$ A tool at a cutting speed of $10.00 \mathrm{~m} / \mathrm{s}$ and a coolant pressure of $20 \mathrm{MPa}$.

Figure 6 shows the relation between and the cutting distance and the surface roughness. The surface roughness (the maximum height " $\mathrm{Rz}$ ") increases with the increase of the cutting distance. The flank wear width increases with the increase of the cutting distance as shown in Fig. 4, and the surface roughness increases with the increase of the cutting distance, too. This shows the same tendency as conventional wet cutting without high-pressure coolant supplied.

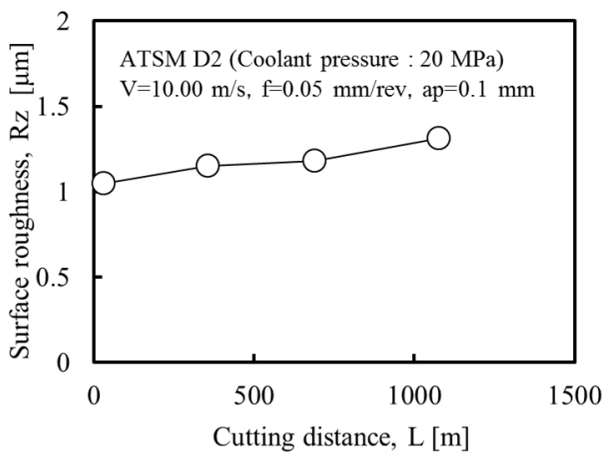

Figure 6: Relation between cutting distance and surface roughness in high-pressure coolant cutting with $\mathrm{cBN}$ A tool at a cutting speed of $10.00 \mathrm{~m} / \mathrm{s}$. 


\section{Conclusions}

In this study, hardened steel was turned with high-pressure coolant supplied, the chip configurations, the tool wear and the surface roughness were experimentally investigated. The hardened steel used was an ASTM D2 cold-worked die steel (60HRC).

The results are as follows:

(1) In turning with high-pressure coolant supplied, the effectiveness of chip breaking performance was improved. In this case, the chip length was shorter with the increase of the coolant pressure, and the chip length was longer with the increase of the cutting speed.

(2) In the case of a cutting speed of $10.00 \mathrm{~m} / \mathrm{s}$, large wear on the flank face was observed in dry cutting. It was possible to suppress the tool wear on the flank face with high-pressure coolant supplied.

(3) In the high-pressure coolant cutting method of hardened steel with a cBN tool at a cutting speed of $10.00 \mathrm{~m} / \mathrm{s}$, the cBN grain size of $5.0 \mu \mathrm{m}, 45$ $\mathrm{cBN}$ grain/55 binding phase and main element of the binder phase of TiCN-Al was an effective tool material. And, the surface roughness by cutting with this $\mathrm{cBN}$ tool was almost constant up to a cutting distance of $1080 \mathrm{~m}$.

\section{Acknowledgements}

We would like to thank TOKUPI Corporation (3-167 Otake Yao Osaka, 572-8530, JAPAN) for their support in the turning test, which enabled this work to be carried out. The authors would also like to express thanks for the cooperation of Tungaloy Corporation for the supply of $\mathrm{cBN}$ inserts.

\section{References}

[1] Gérard Poulachon, B.P. Bandyopadhyay, I.S. Jawahir, Sébastien Pheulpin, Emmanuel Seguin, The influence of the microstructure of hardened tool steel workpiece on the wear of PCBN cutting tools, International Journal of Machine Tools \& Manufacture, 43, pp. 139-144, 2003.

[2] Gérard Poulachon, B.P. Bandyopadhyay, I.S. Jawahir, Sébastien Pheulpin, Emmanuel Seguin, Wear behavior of $\mathrm{CBN}$ tools while turning various hardened steels, Wear, 256, pp. 302-310, 2004.

[3] G.K. Dosbaeva, M.A. El Hakim, M.A. Shalaby, J.E. Krzanowski, S.C. Veldhuis, Cutting temperature effect on PCBN and CVD coated carbide tools in hard turning of D2 tool steel, Int. Journal of Refractory Metals and Hard Materials, 50, pp. 1-8, 2015.

[4] J.A. Arsecularatne, L.C. Zhang, C. Montross, P. Mathew, On machining of hardened AISI D2 steel with PCBN tools, Journal of Materials Processing Technology, 171, pp. 244-252, 2006.

[5] J. Guddat, R. M'Saoubi, P. Alm, D. Meyer, Hard turning of AISI 52100 using PCBN wiper geometry inserts and the resulting surface integrity, 
Procedia Engineering (1st CIRP Conference on Surface Integrity (CSI)), 19, pp. 118-124, 2011.

[6] K. Shintani, H. Katoh, et al., Cutting Performance of CBN Tools in Machining of Austempered Bainitic Spheroidal Graphite Cast Iron, Journal of Japan Soc. Precision Engineering, 56(12), pp. 2261-2266, 1990 (in Japanese).

[7] K. Itakura, M. Kuroda, Y. Doi, H. Tsukamoto, Y. Ariura, High Speed Cutting of Super Heat Resisting Alloy Inconel 718 -On the Finish Cutting with High Pressurized Cutting Fluid-, 66, pp. 1611-1615, 2000 (in Japanese).

[8] E.O. Ezugwu, J. Bonney, Effect of high-pressure coolant supply when machining nickel-base, Inconel 718, alloy with coated carbide tools, Journal of Materials Process Technology, 152-154, pp. 1045-1050, 2004.

[9] E.O. Ezugwu, R.B. Da Silva, J. Bonney, Á.R. Machado, Evaluation of the performance of $\mathrm{CBN}$ tools when turning $\mathrm{Ti}-6 \mathrm{Al}-4 \mathrm{~V}$ alloy with high pressure coolant supplies, International Journal of Machine Tools and Manufacture, 45(9), pp. 1009-1014, 2005.

[10] E.O. Ezugwu, J. Bonney, Y. Yamane, An overview of the machinability of aeroengine alloys, Journal of Materials Processing Technology, 134(2), pp. 233-253, 2003.

[11] E.O. Ezugwu, High speed machining of aero-engine alloys, Journal of the Brazilian Society of Mechanical Sciences and Engineering, 26(1), pp. 1-11, 2004.

[12] Kato H., Shintani K., Fujimura Y., Wear Performance of CBN Tool in Machining of ADI, Trans. of JSME, Series C, 57(541), pp. 3027-3031, 1991 (in Japanese).

[13] P.C Jindal, A.T. Santhanam, U. Schleinkofer, A.F Shuster, Performance of PVD TiN, TiCN, and TiAlN coated cemented carbide tools in turning, International Journal of Refractory Metals and Hard Materials, 17, pp. 163-170, 1999.

[14] Te-Hua Fang, Sheng-Rui Jian, Der-San Chuu, Nanomechanical properties of TiC, TiN and TiCN thin films using scanning probe microscopy and nanoindentation, Applied Surface Science, 228, pp. 365-372, 2004.

[15] J. Takadoum, H. Houmid Bennani, M. Allouard, Friction and wear characteristics of TiN, TiCN and diamond-like carbon films, Surface and Coating Technology, 88, pp. 232-238, 1996. 